Check for updates

Cite this: RSC Adv., 2019, 9, 27231

Received 20th May 2019

Accepted 31st July 2019

DOI: $10.1039 / c 9 r a 03805 a$

rsc.li/rsc-advances

\section{Carbonisation temperature dependence of electrochemical activity of nitrogen-doped carbon fibres from electrospinning as air-cathodes for aqueous-alkaline metal-air batteries $\uparrow$}

\author{
Markus Gehring, (D) *ab Hermann Tempel, (D) a Alexandre Merlen, (D) \\ Roland Schierholz, (D) a Rüdiger-A. Eichel (D) ab and Hans Kungl (D) a
}

\begin{abstract}
Poly-acrylonitrile (PAN)-derived carbon fibres were characterised as air electrode frameworks for aqueousalkaline metal-air batteries, focussing on the influence of the carbonisation temperature on the structure and electrochemical properties. Elemental composition, (atomic) structure, electrical conductivity, and electrochemical performance related to the oxygen reduction were investigated for electrodes carbonised in the range from $300{ }^{\circ} \mathrm{C}$ to $1400{ }^{\circ} \mathrm{C}$. Chemical and structural properties were analysed using elemental analysis, XPS, SEM, and Raman spectroscopy; electrical conductivities of the fibre networks were examined by four-point probe measurements. Electrochemical properties were evaluated using linear sweep voltammetry in $6 \mathrm{M} \mathrm{KOH}$ by the open circuit potentials, the cathodic current densities at given overpotentials, and required overpotentials at given current densities. The highest current density was obtained from fibres carbonised at $850{ }^{\circ} \mathrm{C}$. The connection between the fibre characteristics and electrochemical properties are discussed, highlighting the importance of the nitrogen bonding state. The results provide a base for the development of high performance air electrodes.
\end{abstract}

\section{Introduction}

Over the last two decades, metal-air batteries have (re-)emerged as a potential energy storage system, because of their high theoretical energy densities; environmental friendliness; and abundant, lowcost materials. Primary Zn-air systems have been commercialised for low-power applications, but recent developments in the energy sector have led to a demand in better performing and rechargeable battery systems. ${ }^{1-3}$

Recent reports on primary and secondary aqueous-alkaline metal-air battery systems, such as the $\mathrm{Zn}$-air, ${ }^{1} \mathrm{Fe}-$ air, ${ }^{4,5}$ and Siair ${ }^{5}$ systems, have stressed the points that currently available anodes are performing well and that the full cell performance is limited mainly by the air cathode. ${ }^{6}$ During discharge the overall cell voltage is reduced as a result of the high over-potentials in the cathode, and there is a demand for optimisation of the employed catalyst materials as well as the electrode architecture.,

\footnotetext{
${ }^{a}$ Forschungszentrum Jülich $\mathrm{GmbH}$, Institute of Energy and Climate Research Fundamental Electrochemistry (IEK-9), 52425 Jülich, Germany.E-mail: m.gehring@ fz-juelich.de; Fax: +492461 61-4155; Tel: +49 2461 61-96689

${ }^{b}$ Rheinisch-Westfälische Technische Hochschule Aachen, Institute of Physical Chemistry, 52056 Aachen, Germany

'IM2NP, CNRS, Aix-Marseille Université, Université de Toulon, Toulon, France

$\dagger$ Electronic supplementary information (ESI) available. See DOI: 10.1039/c9ra03805a
}

Typically, air cathodes consist of several layers: a hydrophobic membrane, such as porous PTFE; a Ni-based current collector; a gas diffusion layer, composed of pressed carbon powder and PTFE; and a catalytically active layer. ${ }^{1,7}$ Improvements and further development of the air cathode can follow either of two routes: an iterative improvement of the state-ofthe-art design or fundamentally new design approaches. In this work electrodes composed of a mat of mechanically selfsupporting electrospun carbon fibres from poly-acrylonitrile (PAN) are presented as such a new-design approach.

Electrospinning, unlike traditional wet-spinning, results in non-woven fibre mats composed of fibres with diameters in the sub-micrometre range and a large surface areas. ${ }^{8}$ As a result, the carbon fibre mats derived from electrospinning feature a number of advantages over the-traditionally pressedcarbon powders: the pore structure and the surface properties can be tailored to the application at hand. ${ }^{9}$ The resulting carbonised fibre mats are self-standing and extremely lightweight. Most importantly, chemical composition, structure, and surface morphology of the fibres can be predetermined by choosing appropriate precursors and processing conditions. ${ }^{9}$

The precursors are, typically, polymer solutions that can even be further enhanced with additives, such as catalysts, that can be directly integrated into the fibres. ${ }^{9-11}$ This may reduce the amount of additional preparation steps. The precursor material can be chosen from a wide range of polymers, thus the final 
composition of the fibres can be influenced a priori. Most importantly, hetero-atom doping becomes easily accessible by using polymers that contain e.g. nitrogen, such as PAN.9,12,13

PAN is a thoroughly investigated model material both for the production of carbon fibres as well as electrospinning. ${ }^{8}$ The carbon fibres are obtained by heat treatment of the polymer fibres under protective atmosphere. The complex carbonisation mechanism of PAN has been studied extensively by many groups since initial reports in the early 1960 s by Shindo. ${ }^{\mathbf{1 4 , 1 5}}$

In terms of electrochemistry, PAN is a suitable precursor material for carbon, as the carbon yields are high; the surface area of the fibres increase with carbonisation temperature; ${ }^{16}$ and, most importantly, PAN derived carbon typically retains at least some of its nitrogen, depending on the carbonisation temperature applied. ${ }^{17}$ Nitrogen-doped carbon has an inherent auto-catalytic activity towards oxygen redox chemistry. In the last decades, nitrogen-doped carbon has been proposed as a possible metal-free catalyst for the oxygen reduction reaction (ORR) and the oxygen evolution reaction (OER). Accordingly, doping with other hetero-atoms has been shown to enhance the activity, as well. This includes boron-doping, ${ }^{18-20}$ sulphurdoping, ${ }^{20}$ and phosphorous-doping. ${ }^{20,21}$ All of these dopants have been shown to influence the catalytic activity, but also structural properties, such as the active surface area. ${ }^{8}$ The mechanisms behind the activity, however, have remained a point of discussion. ${ }^{22-27}$

The catalytic route for the ORR on platinum is well understood. ${ }^{28}$ However, it has been established that the catalytic route on nitrogen-doped carbons is a different one ${ }^{29}$ and the activity, in very general terms, originates from the interaction of the carbon $\pi$-system with the nitrogen lone pair. ${ }^{30}$ The nitrogen doping increases the electron density near the carbon's Fermi level, which facilitates the breaking of the $\mathrm{O}-\mathrm{O}$ bond by transferring electrons from the carbon $\pi$-system to the oxygen's antibonding $2 \sigma_{\mathrm{p}}{ }^{*}$ or $2 \pi^{*}$ orbitals. ${ }^{30,31}$ The overall ORR equation in aqueous-alkaline media is given by eqn (1).

$$
\mathrm{O}_{2(\mathrm{~g})}+2 \mathrm{H}_{2} \mathrm{O}_{(\mathrm{l})}+4 \mathrm{e}^{-} \rightleftharpoons 4 \mathrm{OH}_{(\mathrm{aq})}^{-} ; E_{0}=0.04 \mathrm{~V} v s . \mathrm{RHE}^{3,29}
$$

Initially, oxygen will adsorb onto a $\beta$-carbon site (eqn (2))

$$
\mathrm{O}_{2(\mathrm{aq})} \rightleftharpoons \mathrm{O}_{2(\mathrm{ads})}
$$

There are different modes in which oxygen can adsorb to a (catalyst) surface. More recent calculations have found that the end-on oxygen adsorption (Pauling model) is energetically favourable to side-on adsorption (Yeager model) on nitrogendoped carbon. $^{29}$ The subsequent reaction is determined primarily by the adsorption mode, with end-on adsorption leading to a so-called associative mechanism and side-on adsorption to an dissociative mechanism.

In the associative mechanism, as a first step, the adsorbed oxygen forms adsorbed hydroperoxide (eqn (3)) and the $\mathrm{O}-\mathrm{O}$ bond is broken subsequently, as detailed by eqn (4). This mechanism corresponds to the energetically favourable $4 \mathrm{e}^{-}$ mechanism. ${ }^{32}$ The peroxide then disproportionates (eqn (4)), forming adsorbed hydroxide (eqn (5)). Lastly, the remaining hydroxide desorbs (eqn (6)).

$$
\begin{gathered}
\mathrm{O}_{2(\mathrm{ads})}+\mathrm{H}_{2} \mathrm{O}_{(\mathrm{l})}+\mathrm{e}^{-} \rightleftharpoons \mathrm{OOH}_{(\mathrm{ads})}+\mathrm{OH}^{-}{ }_{(\mathrm{aq})} \\
\mathrm{OOH}_{(\mathrm{ads})}+\mathrm{e}^{-} \rightleftharpoons \mathrm{O}_{(\mathrm{ads})}+\mathrm{OH}^{-}{ }_{(\mathrm{aq})} \\
\mathrm{O}_{(\mathrm{ads})}+\mathrm{H}_{2} \mathrm{O}_{(\mathrm{l})}+\mathrm{e}^{-} \rightleftharpoons \mathrm{OH}_{(\mathrm{ads})}+\mathrm{OH}^{-}{ }_{(\mathrm{aq})} \\
\mathrm{OH}_{(\mathrm{ads})}+\mathrm{e}^{-} \rightleftharpoons \mathrm{OH}^{-}{ }_{(\mathrm{aq})}
\end{gathered}
$$

In the dissociative mechanism the oxygen $\mathrm{O}-\mathrm{O}$ bond is broken as the first step (eqn (7)) followed by the $2 \mathrm{e}^{-}$mechanism (per oxygen atom) (eqn (5) and (6)). ${ }^{29,32}$

$$
\mathrm{O}_{2(\mathrm{ads})} \rightleftharpoons 2 \mathrm{O}_{(\mathrm{ads})}
$$

However, both experimental and theoretical studies have not reached a conclusion, as to which nitrogen species is causing the catalytic activity. Both types of studies have found arguments for attributing the enhancement to either pyridinic nitrogen ${ }^{33}$ or graphitic nitrogen. ${ }^{23}$ Based on DFT calculations, Kim and co-workers have proposed a ring-opening mechanism, involving initially graphitic nitrogen, which becomes pyridinic nitrogen upon ring-opening, in an attempt to reconcile the two points of view. ${ }^{32}$ Also, these results underline the importance of edge-type nitrogen, which has generally been found to be more active towards ORR. ${ }^{30}$

Overall, using PAN-derived electrospun carbon fibres as an air-cathode framework is a sensible approach, as has been demonstrated by other groups, ${ }^{\mathbf{1 3}}$ but a deeper understanding of the unmodified material is still required, when high performance is sought. This entails a detailed evaluation of the parameters of both the electrospinning process and the postprocessing.

In this paper the relationship between the nitrogen content; bonding situation; fibre morphology and structure; and the electrochemical properties are investigated. The main focus are the gradual changes in the PAN-derived fibres during carbonisation in a wide carbonisation temperature range from $300{ }^{\circ} \mathrm{C}$ to $1400{ }^{\circ} \mathrm{C}$.

\section{Experimental}

\subsection{Synthesis of carbon fibres and electrode preparation}

Solutions of $10 \mathrm{wt} \%$ poly-acrylonitrile (PAN, $M_{\mathrm{W}}=150000 \mathrm{~g}$ $\mathrm{mol}^{-1}$; BOC Sciences, USA) in $N, N$-dimethylformamide (DMF; Merck, France) were prepared by stirring the mixture at roomtemperature for a minimum of three days. The solution was filled into a syringe and pumped into the electrospinning chamber (FEM Technologies, The Netherlands) with a fixed flowrate of $40 \mu \mathrm{L} \mathrm{min}{ }^{-1}$. The distance between the nozzle and the collector was set to $15 \mathrm{~cm}$. The voltage at the nozzle was set to $21 \mathrm{kV}$ and at the collector to $-4 \mathrm{kV}$. The rotating drum collector was covered with non-adhesive paper and its rotation speed was set to $1500 \mathrm{rpm}$.

For all samples, the temperature in the spinning chamber was $25{ }^{\circ} \mathrm{C}$ with a relative humidity of $40 \%$. The spinning time 
was $6 \mathrm{~h}$ per sample. The obtained fibre mats were stabilised in air at $250{ }^{\circ} \mathrm{C}$ overnight and subsequently carbonised at temperatures between $300{ }^{\circ} \mathrm{C}$ and $1400{ }^{\circ} \mathrm{C}$ for $3 \mathrm{~h}$ under argon. The heating rate was $5 \mathrm{~K} \mathrm{~min}^{-1}$ and the cooling rate was 3.33 $\mathrm{K} \min ^{-1}$.

The carbonised samples were cut into pieces of approximately $3 \mathrm{~cm}$ by $3 \mathrm{~cm}$. A hydrophobic PTFE membrane (PMV10L; Porex, USA) was applied by means of hot rolling at $120{ }^{\circ} \mathrm{C}$.

\subsection{Physical characterisation}

SEM images were recorded using a Helios NanoLab 460F1 (FEI Europe) with an acceleration voltage of $20 \mathrm{kV}$. The samples were attached to the sample holder using a double-faced graphite tape and conductivity was further improved by applying a copper tape to both the sample and the graphite tape. The fibre diameters were determined from the resulting images using a total of 100 fibres per sample from five representative spots of each sample.

Raman spectra were obtained using a Bruker Senterra at room-temperature in ambient atmosphere. The excitation wavelength was $532 \mathrm{~nm}$ with a power of $2 \mathrm{~mW}$. The signals of two subsequent measurements of $30 \mathrm{~s}$ each were added together, to improve the signal to noise ratio (Co-addition mode).

For the elemental analysis $2 \mathrm{mg}$ of sample was burned in the elemental analyser (VarioelCube, Elementar) for both CHN and $\mathrm{O}$ analyses. The signal was detected using a heat conductivity detector.

X-ray photo spectroscopy (XPS) was performed with a Phi5000 VersaProbe II (ULVAC-Phi Inc., USA). Spectra were recorded using $\mathrm{Al}-\mathrm{K} \alpha$ radiation $(1.486 \mathrm{keV})$ at $50 \mathrm{~W}$ with a resolution of $0.1 \mathrm{eV}$ and a spot-size of $200 \mu \mathrm{m}$.

Electrical resistance was recorded using a custom-made four-point probe device with a square arrangement of stainless steel tips with a tip distance $(s)$ of $2.54 \mathrm{~mm}$. Resistance values were detected using a table top multimeter (2701 Integra, Keithley, USA). The conductivity $\sigma\left(\mathrm{S} \mathrm{cm}^{-1}\right)$ was calculated from the measured resistance $R\left(\Omega \mathrm{sq}^{-1}\right)$ using the equation used for the $3 \mathrm{D}$ bulk-resistivity $\rho(\Omega \mathrm{cm})$ in the square set-up (eqn $(8)):^{34}$

$$
\sigma:=\rho^{-1}=\frac{2-\sqrt{2}}{2 \pi s} \times \frac{1}{R}
$$

\subsection{Electrochemical investigation}

Aqueous $6 \mathrm{M} \mathrm{KOH}$ was used as electrolyte. Appropriate amounts of $\mathrm{KOH}$ (85\%; VWR, France) were dissolved in de-ionised water (0.055 $\mu \mathrm{S} \mathrm{cm}^{-1}$; Purelab flex, Elga Veolia, United Kingdom).

The electrochemical investigation was performed in a halfcell setting, using a commercially available cell (FlexCell-PP, Gaskatel, Germany). The counter electrode was a platinum wire and a mercury/mercury oxide electrode (MMO; ALS, Japan) was used as a reference electrode. Unless stated otherwise, the cell was assembled and equilibrated at OCP for $1 \mathrm{~h}$. Linear potential sweep voltammetry (LSV) was performed with a scan rate of $1 \mathrm{mV} \mathrm{s}^{-1}$ in a potential window between $0.2 \mathrm{~V} v s$. MMO and $-0.5 \mathrm{~V}$ vs. MMO. Measurements were performed sequentially after $1 \mathrm{~h}, 2 \mathrm{~h}, 4 \mathrm{~h}, 8 \mathrm{~h}$ and $12 \mathrm{~h}$ for each sample, between each measurement cells were left at OCP.

\section{Results and discussion}

\subsection{SEM analysis of fibres}

The overall morphology of the fibre mats after carbonisation was investigated using SEM. Images of selected samples are shown in Fig. 1. All samples exhibit a fibrous morphology with smooth surfaces. The fibre mats underwent significant macroscopic shrinking during the carbonisation process, which, microscopically, resulted in a lower volume of in-between space in the fibre mats.

The shrinking of the fibres is also reflected in the fibre diameters themselves. The mean diameters decrease with carbonisation temperature as shown in Fig. 2 .

The diameters vary between $270 \mathrm{~nm}$ and $470 \mathrm{~nm}$. This is well within the typical range that can be found in literature for comparable fibre systems. ${ }^{35}$ The shrinking is most pronounced in the temperature range of $400{ }^{\circ} \mathrm{C}$ and $600{ }^{\circ} \mathrm{C}$ and the diameters are similar for samples carbonised above $600{ }^{\circ} \mathrm{C}$.

\subsection{Elemental composition and X-ray photoelectron spectroscopy (XPS)}

Elemental analysis shows that the relative carbon content in oxidatively stabilised fibres $((52.7 \pm 0.1) \mathrm{wt} \%)$ is lower than in PAN powder $((66.6 \pm 0.2) \mathrm{wt} \%)$ and PAN fibres $(66.1 \pm 1.3) \mathrm{wt} \%)$. This is directly related to the oxidation of the fibres. The elemental composition of the as spun fibres is equivalent to that of the powder, which suggests that the chemical composition does not change during the electrospinning process.

During carbonisation the relative carbon content increases. The increase is higher for higher carbonisation temperatures. The carbon content is $53.7 \mathrm{wt} \%$ for fibres carbonised at $300{ }^{\circ} \mathrm{C}$, and $98.4 \mathrm{wt} \%$ for fibres carbonised at $1400^{\circ} \mathrm{C}$. Fig. 3 shows the
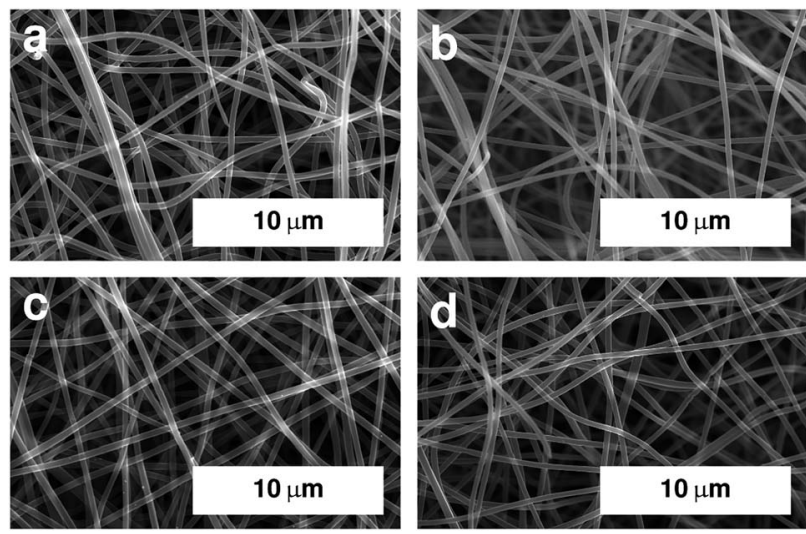

Fig. 1 SEM images of electrospun PAN fibres after stabilisation in air at $250{ }^{\circ} \mathrm{C}$ and carbonisation under argon at (a) $600{ }^{\circ} \mathrm{C}$, (b) $800{ }^{\circ} \mathrm{C}$, (c) $1000^{\circ} \mathrm{C}$, and (d) $1250^{\circ} \mathrm{C}$. Image for sample carbonised at $400{ }^{\circ} \mathrm{C}$ is shown in Fig. S1.† 


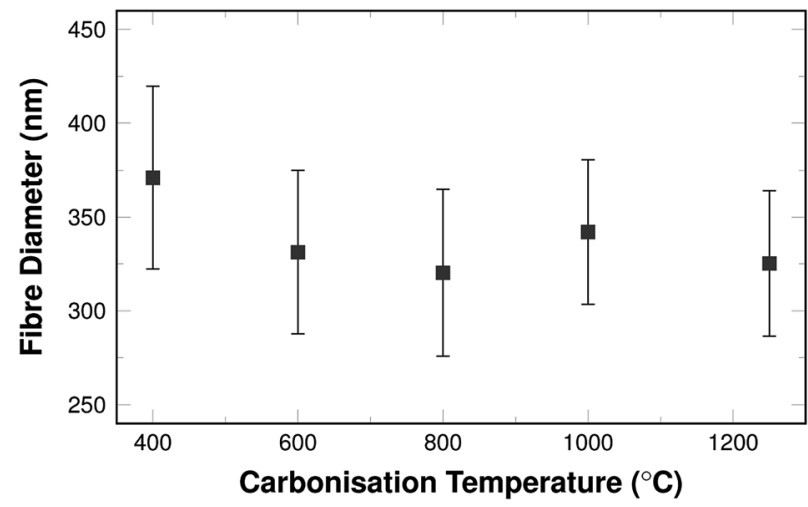

Fig. 2 Fibre diameters as a function of carbonisation temperature.

different elemental compositions for all investigated temperatures.

It becomes clear that the increase of the relative carbon content is the result of a loss of nitrogen, oxygen, and hydrogen. The changes in oxygen and nitrogen contents differ in slope depending on the carbonisation temperature. Three distinctive sections can be identified and assigned to three temperature ranges. Between $300{ }^{\circ} \mathrm{C}$ and $650{ }^{\circ} \mathrm{C}$ the oxygen content is reduced from $24 \mathrm{wt} \%$ to $14 \mathrm{wt} \%$, while the nitrogen content remains stable at about $21 \mathrm{wt} \%$. In the second section between $650{ }^{\circ} \mathrm{C}$ and $1000{ }^{\circ} \mathrm{C}$, the oxygen content is further reduced only slightly, to $11 \mathrm{wt} \%$, while the nitrogen content decreases from $21 \mathrm{wt} \%$ to about $7.5 \mathrm{wt} \%$. At temperatures above $1000{ }^{\circ} \mathrm{C}$, the oxygen content is reduced significantly to below $1 \mathrm{wt} \%$, and to almost $0 \mathrm{wt} \%$ when carbonising at $1400{ }^{\circ} \mathrm{C}$. The nitrogen content is further reduced, at a lower rate than before, to $2.5 \mathrm{wt} \%$, which remain in the material. Hydrogen is removed slowly but steadily in the entire temperature range from $3 \mathrm{wt} \%$ to almost $0 \mathrm{wt} \%$ (Fig. 3).

It has to be noted, that not only the relative amount of hetero-atoms is reduced, but also the absolute weight of the fibres. This weight loss results from the removal of oxygen, nitrogen, and hydrogen as gases in various combinations, but foremost as $\mathrm{N}_{2}, \mathrm{H}_{2}, \mathrm{NH}_{3}, \mathrm{HCN}$, and $\mathrm{H}_{2} \mathrm{O} .{ }^{15,36}$

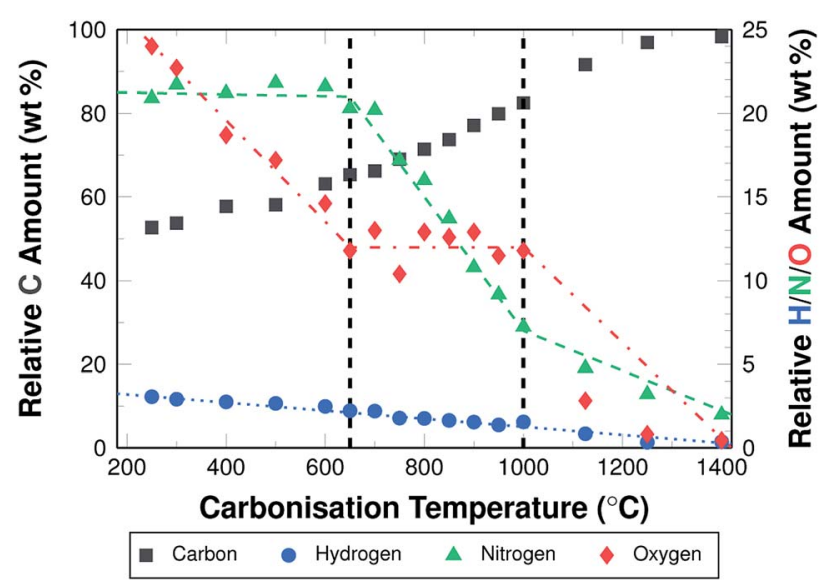

Fig. 3 Elemental analysis $(\mathrm{H}, \mathrm{C}, \mathrm{N}$, and $\mathrm{O})$ of stabilised fibre mats and carbonised fibre mats.
The ratios of amounts of substance from the elemental analysis (Fig. 4), show changes in the chemical composition of the material compared to the PAN repetition unit. This implies pronounced changes in the atomic structure of the fibres from polymeric PAN towards graphite-like carbon. This transformation is indicated by the increasing deviation of the initial $3 n_{\mathrm{N}} / n_{\mathrm{C}}$ ratio, where $n_{\mathrm{N}}$ is the amount of substance of nitrogen and $n_{\mathrm{C}}$ that of carbon. The ratio increases slightly when comparing as-spun fibres to stabilised fibres, as a result of the oxidation, but decreases from 1.03 to 0.05 throughout the investigated temperature range during carbonisation.

The $3 n_{\mathrm{N}} / n_{\mathrm{C}}$ ratio follows a sigmoidal trend during carbonisation. It can be described by three phases, based on the carbonisation temperature, similar to the overall development of the nitrogen content (Fig. 3). The decrease progresses rather slowly at temperatures below $600{ }^{\circ} \mathrm{C}$. At higher temperatures the decrease is more pronounced and the values decrease from 0.9 at $600{ }^{\circ} \mathrm{C}$ to 0.2 at $1000{ }^{\circ} \mathrm{C}$. At temperatures above $1000{ }^{\circ} \mathrm{C}$ the ratio is reduced to very low values at $1400^{\circ} \mathrm{C}$, as the nitrogen has been almost completely removed.

The ratio of hydrogen to carbon $\left(n_{\mathrm{H}} / n_{\mathrm{C}}\right)$ is higher than that of the repetition unit only for un-stabilised PAN repetition units. The higher values may be the result of various influences such as PAN end groups, adsorbed species (such as water), measurement errors, or impurities. The ratio for stabilised fibres is 0.7 as a result of the oxidative stabilisation, where the nitrile groups polymerise to conjugated imines and the related removal of gaseous $\mathrm{H}_{2}$ and $\mathrm{NH}_{3}$ takes place. The ratio values decrease from 0.7 to 0 almost linearly. This removal process results in an aromatic ring structure. ${ }^{15,37}$

The nitrogen content in and of itself is not a sufficient indicator for catalytic activity. Therefore, the bonding situation of the nitrogen on the surface of the fibres is investigated via XPS. Fig. 5 shows the development of the signal intensities for binding energies from $395.5 \mathrm{eV}$ to $406.5 \mathrm{eV}$, which can be attributed to different bonding situations of nitrogen in a (graphitic) carbon structure (additional spectra are shown in Fig. S2 and S3†).

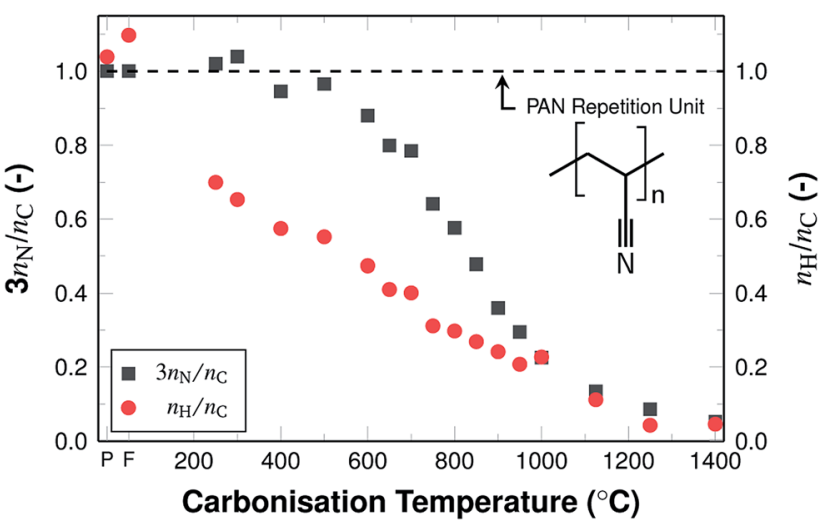

Fig. 4 Ratios of amounts of substance of nitrogen and carbon (grey) and hydrogen and carbon (red), relative to the ratio in the PAN repetition unit (black dashed line). P and $\mathrm{F}$ indicate PAN powder and PAN fibres, respectively. 
A common approach in attributing the peaks to bonding types is as follows: the peak at $398.7 \mathrm{eV}$ corresponds to pyridinic nitrogen, the peak at $400.3 \mathrm{eV}$ to pyrrolic nitrogen, the peak at $401.2 \mathrm{eV}$ to graphitic nitrogen, and the peak at $402.8 \mathrm{eV}$ to pyridinic N-oxides. ${ }^{26}$ Due to their interaction and the fitting procedure itself, the peaks may shift their position slightly to both higher and lower binding energies.

From a practical point of view, two temperature ranges have to be distinguished. For the samples carbonised below and at $500{ }^{\circ} \mathrm{C}$, the spectra were fitted with only three peaks. In these cases a distinction between the graphitic nitrogen and the $\mathrm{N}$ oxides is not possible, although it may be assumed that the signal stems mostly from N-oxides. The spectra of the samples carbonised at $600{ }^{\circ} \mathrm{C}$ and above were accordingly fitted with four peaks, distinguishing between the two species.

The amounts of nitrogen species and their development with carbonisation temperature are shown, in detail, in Fig. 6. The development of the relative fraction of each species as results from the area intensities are shown in Fig. 6a. The weight fraction of the nitrogen species determined by multiplying the relative fraction of nitrogen species according to XPS (Fig. 6a) and the nitrogen content from the elemental analysis (Fig. 3) is shown in Fig. 6b.

In the low temperature range up until $600{ }^{\circ} \mathrm{C}$, the signal intensity attributed to pyrrolic and mixed graphitic and $\mathrm{N}$ oxides decrease. In turn, the intensity ratio of pyridinic nitrogen increases from $40.3 \%$ to $57.1 \%$. At $600{ }^{\circ} \mathrm{C}$, the signal intensity of pyridinic nitrogen has a maximum, both in terms of relative intensity and weight fraction. In the temperature range above $600{ }^{\circ} \mathrm{C}$, the signal intensity for pyridinic nitrogen decreases from $57.1 \%$ at $600{ }^{\circ} \mathrm{C}$ to $0 \%$ at $1400{ }^{\circ} \mathrm{C}$. The signal intensity of pyrrolic nitrogen decreases throughout the entire investigated temperature range from $46.5 \%$ after stabilisation in air at $250{ }^{\circ} \mathrm{C}$ to $0 \%$ after carbonising at $1400{ }^{\circ} \mathrm{C}$ in argon. The signal intensity of graphitic nitrogen, once it can be deconvoluted individually, increases from initially $12.8 \%$ at $600{ }^{\circ} \mathrm{C}$ to $100 \%$ at $1400{ }^{\circ} \mathrm{C}$. The signal intensity attributed to N-oxides that can be identified in this temperature range increases from $2 \%$ at $600{ }^{\circ} \mathrm{C}$ to $15.1 \%$ at $1250{ }^{\circ} \mathrm{C}$, but is then reduced to $0 \%$ at $1400{ }^{\circ} \mathrm{C}$.

It is possible that the minimum of the $\mathrm{N}$-oxide signal intensity at $600{ }^{\circ} \mathrm{C}$ results from a systematic error of interpretation, when the XPS signal is fitted with three instead of four peaks (Fig. 5). It may in fact be constant in the entire carbonisation temperature range until $1250^{\circ} \mathrm{C}$.

Pyrrolic nitrogen, by definition, occurs in five-fold rings as part of $\mathrm{N}-\mathrm{H}$ groups, but not in six-membered ones. Pyridinic and graphitic nitrogen is part of six-membered rings, substituting for a carbon atom in the ideal graphite structure. Pyridinic nitrogen occurs along the edges of a graphene layer, graphitic nitrogen will be part of the bulk area. Graphitic nitrogen will disturb the ordering of the material less than pyridinic nitrogen, which causes less disorder than pyrrolic nitrogen. Hence, the XPS results imply an increasing ordering and an ongoing graphitisation along the temperature axis. Pyridinic nitrogen will most likely dominate in structures with many edges. Large amounts of graphitic nitrogen imply larger clusters of graphitic areas, with fewer edges and defects.

The decreasing trend for the weight fractions of pyrrolic and pyridinic nitrogen (Fig. 6b) is more pronounced than for the relative amounts. Graphitic nitrogen shows a clear maximum of $6 \mathrm{wt} \%$ in the samples carbonised at $800{ }^{\circ} \mathrm{C}$. At $1400{ }^{\circ} \mathrm{C}$ almost all
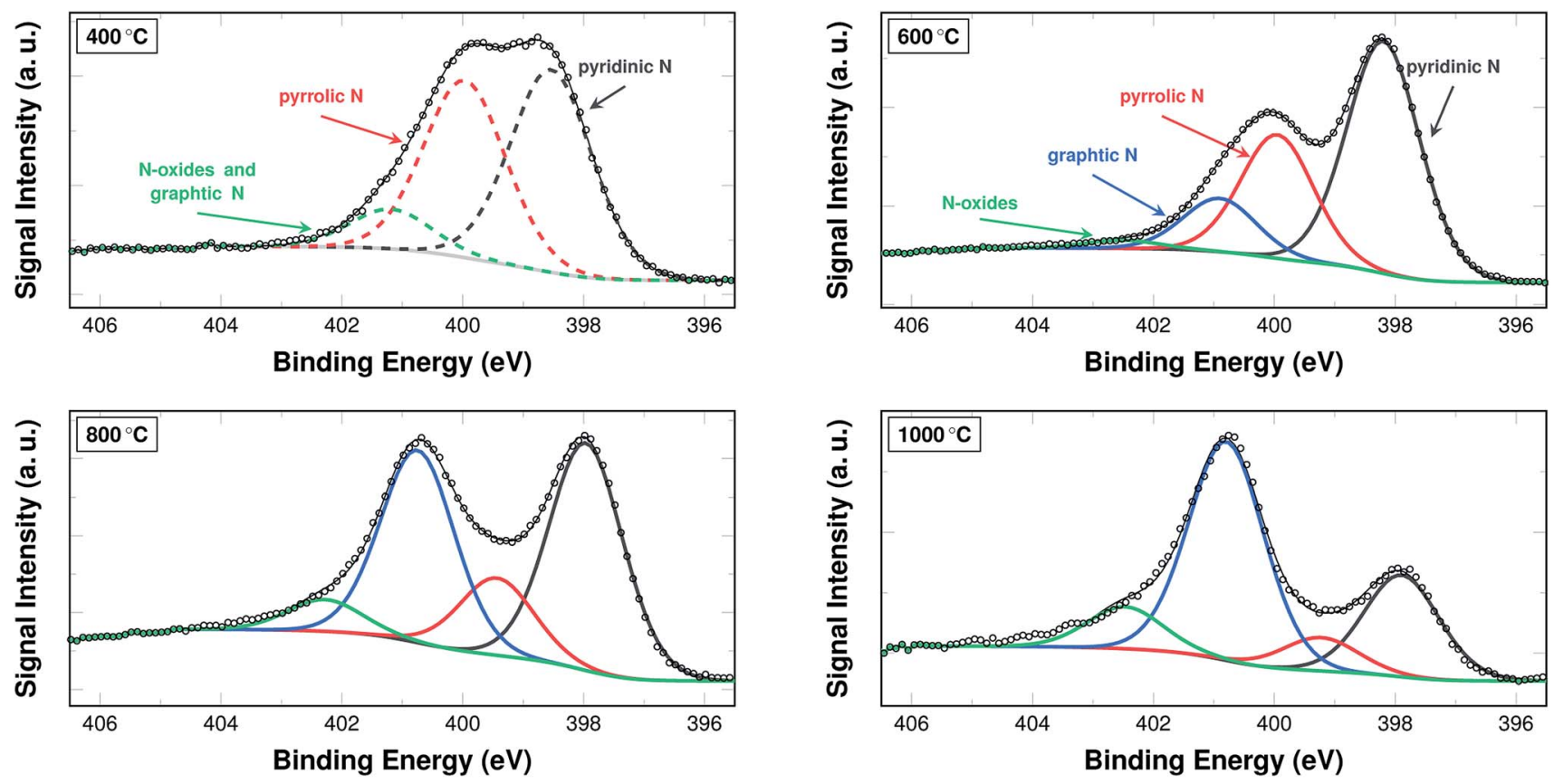

Fig. $5 \mathrm{~N}$ 1s section of XPS spectra of samples carbonised at $400{ }^{\circ} \mathrm{C}, 600{ }^{\circ} \mathrm{C}, 800{ }^{\circ} \mathrm{C}$, and $1000^{\circ} \mathrm{C}$. The spectrum of a sample carbonised at $400{ }^{\circ} \mathrm{C}$ was fitted with three peaks, as the signals for $\mathrm{N}$-oxides and graphitic nitrogen could not be deconvoluted in this case (dashed lines). Spectra of samples carbonised at $600^{\circ} \mathrm{C}, 800^{\circ} \mathrm{C}$, and $1000^{\circ} \mathrm{C}$ were fitted using a total of four peaks (solid lines). 
of the nitrogen present in the material is graphitic, albeit this means only $2 \mathrm{wt} \%$ of the material. This behaviour of the weight fraction of graphitic nitrogen is explained by the increasing trend of the relative fraction with carbonisation temperature, which is counteracted by the decrease in the overall nitrogen content.

\subsection{Raman spectroscopy}

Raman spectra of graphitic carbon materials contain two characteristic peaks. The D peak at around $1355 \mathrm{~cm}^{-1}$, the $\mathrm{G}$ peak at around $1600 \mathrm{~cm}^{-1}$. This is also true for the carbon fibres at hand and the resulting spectra including the $\mathrm{D}$ and $\mathrm{G}$ peaks are shown in Fig. 7.

In materials composed of carbon only, the Raman signal from $900 \mathrm{~cm}^{-1}$ to $1900 \mathrm{~cm}^{-1}$ is the result of a superposition of five overlapping bands caused by the different vibrational modes of carbon that exist independently of graphitic ordering. ${ }^{38,39}$ These peaks are broadened in case of nitrogendoping, as the additional nitrogen leads to additional bands in the Raman shift range from $1630 \mathrm{~cm}^{-1}$ to $1670 \mathrm{~cm}^{-1}$ as well as defects that enable the $\mathrm{A}_{1 \mathrm{~g}}$ mode that is forbidden in ideal graphite. ${ }^{\mathbf{4 0 , 4 1}}$ Additionally, oxygen-containing functional groups, which originate from the oxidative stabilisation, cause $\mathrm{C}=\mathrm{O}$ bands in the range from $1652 \mathrm{~cm}^{-1}$ to $1734 \mathrm{~cm}^{-1}$. $^{40}$
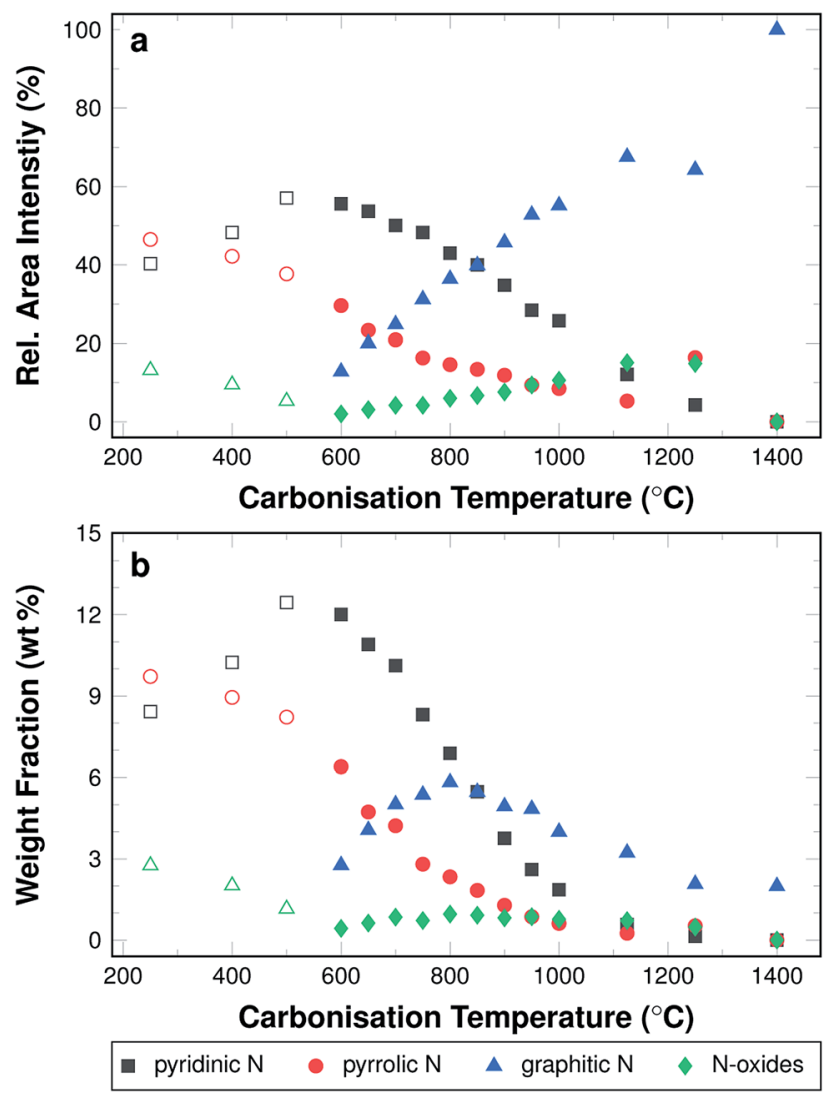

Fig. 6 (a) Relative area intensities of XPS peaks attributed to different types of nitrogen. (b) Weight fractions of individual nitrogen species calculated from a combination of XPS and elemental analysis. The open symbols represent the attribution of the peaks for a fitting with three peaks; the closed symbols for a fitting with four peaks.
The resulting total number of bands in nitrogen- and oxygendoped carbon is very high and the peaks cannot be deconvoluted. The common approach for such cases is a fitting of the two peaks as measured, not taking the several contributions into account individually. ${ }^{38}$ Two variations of this approach are commonly used for fitting: either two Gaussians or a Lorentzian (D peak) and a Breit-Wigner-Fano (BWF) distribution (G peak). The BWF distribution is an asymmetric function, accounting for the additional dopant contributions. The two methods have been discussed at length by Ferrari and Robertson ${ }^{39}$ and in this work, the Lorentz/BWF method was chosen.

Fig. 8 shows the resulting development of the ratio of both the maximum height of the fits $I_{\mathrm{D}}^{\mathrm{h}} / I_{\mathrm{G}}^{\mathrm{h}}$ as well as their areas $I_{\mathrm{D}}^{\mathrm{a}} /$ $I_{\mathrm{G}}^{\mathrm{a}}$, both as a function of the carbonisation temperature.

Both ratios display an exponential decay, with the height intensity ratio decreasing from 1.75 to roughly 1.0 and the area intensity ratio decreasing from 2.9 to about 1.9 . This reduction of the ratio is related to an increase in the graphitic ordering of the material, fewer defects, and a higher number of unperturbed carbon six-fold rings. The more pronounced decrease of the area intensity ratio can readily be explained by the fact that the overall amount of hetero-atoms decreases with carbonisation temperature, leading to a reduction in peak broadening, especially of the D peak. In other words, the fibres display an increase in structural ordering with increasing temperatures throughout the entire temperature range, although the changes are most pronounced in the lower temperature range up to $600{ }^{\circ} \mathrm{C}$.

\subsection{Electrical conductivity}

In general, electrical conductivity is equivalent to high mobility of charge carriers more specifically electrons. Their mobility may be reduced by e.g. grain boundaries, resulting in an increased resistance due to the required charge transfer processes. Electron mobility is enhanced, when electrons are de-localised. In carbon materials this is the case, when a large number of conjugated double-bonds is present, which is especially the case in graphite. The development of the electrical conductivity for the investigated carbon fibre mats is shown in Fig. 9a.

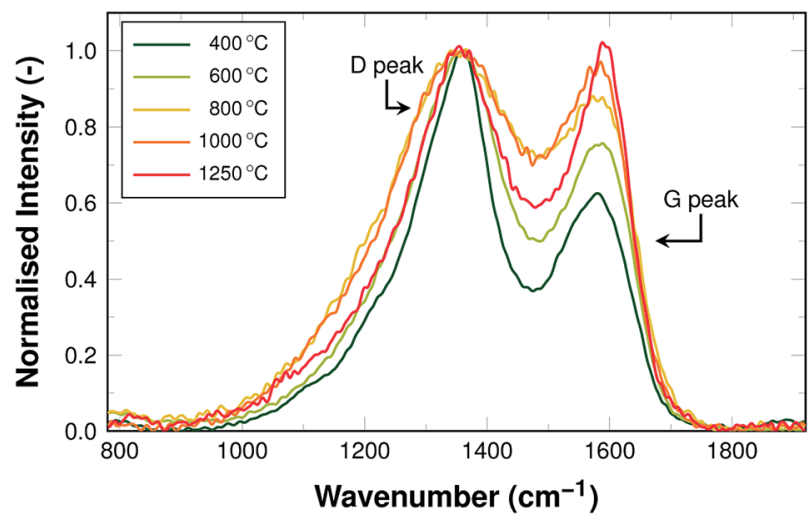

Fig. 7 Raman spectra of samples carbonised at $400{ }^{\circ} \mathrm{C}, 600{ }^{\circ} \mathrm{C}$, $800{ }^{\circ} \mathrm{C}, 1000^{\circ} \mathrm{C}$, and $1250^{\circ} \mathrm{C}$, normalised to the height of the $\mathrm{D}$ peak. 


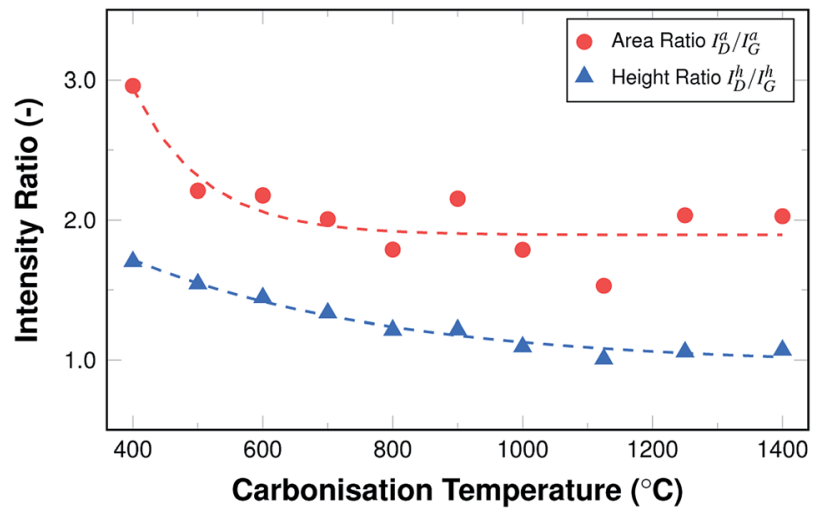

Fig. 8 Raman area and height intensity ratios $I_{D} / l_{G}$ as a function of carbonisation temperature.

High resistances result in a negligible conductivity in the samples carbonised at low temperatures, i.e. below $600^{\circ} \mathrm{C}$. In all likelihood, the $\pi$-system has not yet developed in the material and electrons cannot move freely along the fibres. The threshold temperature, above which conductivity is detectable, lies at around $800{ }^{\circ} \mathrm{C}$. This is consistent with the Raman data, which show decreasing $I_{\mathrm{D}} / I_{\mathrm{G}}$ ratios for samples carbonised at up to $800{ }^{\circ} \mathrm{C}$. This decrease in signal intensity ratio indicates a transformation towards more graphite-like ordering. In terms of increasing conductivity, this makes sense, as the graphite structure is more conductive the fewer structural defects are present. The amount of nitrogen that is not incorporated as graphitic nitrogen decreases, which can be seen in the N 1s XPS data shown in Fig. 6. The structure is, therefore, less perturbed and the conductivity increases.

A logarithmic representation of the conductivity for samples carbonised above $800{ }^{\circ} \mathrm{C}$ is shown in Fig. 9b. Between $800{ }^{\circ} \mathrm{C}$ and $950{ }^{\circ} \mathrm{C}$ the conductivity increases more strongly than between $950{ }^{\circ} \mathrm{C}$ and $1400^{\circ} \mathrm{C}$. This effect may be attributed to the incorporated nitrogen, its amount, as well as its bonding situation. Two effects compete in this case. On the one hand

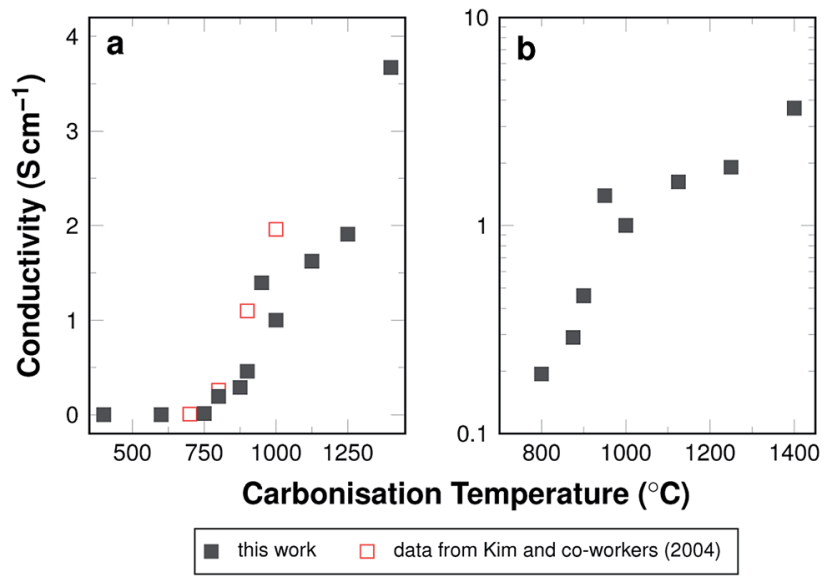

Fig. 9 (a) Calculated conductivity as a function of carbonisation temperature. Reference data from Kim and co-workers. ${ }^{42}$ (b) Logarithmic plot of calculated conductivity as a function of carbonisation temperature in a selected range. nitrogen introduces defects into the ideal graphite system, which is by itself expected to reduce conductivity. On the other hand, nitrogen adds an additional electron to the aromatic system, which is expected to increase the conductivity, as the density of charge carriers in the system is higher. ${ }^{41}$ Also, the defects caused by nitrogen are less influential at higher carbonisation temperatures, where increasing amounts of nitrogen substitute for carbon in the graphitic structure ( $c f$. Fig. 6a).

At high temperatures the overall nitrogen content is very low, so that either of the effects vanish and the material behaves like purely carbonaceous fibres. The strong increase of the conductivity is in good agreement with the conductivity of electrospun carbon fibres from PAN reported by Kim and coworkers ${ }^{42}$ as shown in Fig. 9a. Whether the conductivity in this case is governed by the nitrogen doping or the carbon backbone is subject to discussion. For nitrogen-doped carbon nanofibres derived from the decomposition of carbohydrates in ammonia a maximum of conductivity at intermediate amounts of incorporated nitrogen has been reported. ${ }^{41}$ This is different for the electrospun carbon fibres from PAN carbonised in argon, for which the nitrogen content varies with the carbonisation temperature. In our case, the conductivity increases throughout the investigated carbonisation temperature range with the highest values found for samples carbonised at $1400{ }^{\circ} \mathrm{C}$.

This structural explanation of the development of the electrical conductivity is further supported by the $\mathrm{C} 1 \mathrm{~s}$ range of the XPS spectra (Fig. 10).

The amount of $\mathrm{sp}^{2}$-hybridised (i.e. graphitic) carbon increases from $30 \%$ in stabilised fibres to $60 \%$ in fibres carbonised at $600{ }^{\circ} \mathrm{C}$. It remains at this value for carbonisation temperatures up to $950{ }^{\circ} \mathrm{C}$. In samples carbonised at higher temperatures, the amount of $\mathrm{sp}^{2}$-hybridised carbon lies at well above $95 \%$. In the same temperature range the $\pi \rightarrow \pi^{*}$ transition becomes detectable and this further supports the theory that the material may display significant conductivity only then.

This behaviour is also consistent with the bonding situation of nitrogen. The XPS results showed that almost all available nitrogen is incorporated as graphitic nitrogen substituting for carbon in the graphitic structure increasingly with carbonisation temperature, which has been discussed above ( $c f$. Fig. 6). In general, this means the material is increasingly graphitised, as was already discussed based on the Raman data and the higher the degree of graphitisation, the more pronounced the influence of the conjugated $\pi$-system.

Also, it should also be noted that there is an structural overlap of the $\pi \rightarrow \pi^{*}$ transition satellite and the signal of carbonyl and carboxyl groups, which means that in cases where the transition satellite is not accounted for, the other functional groups may be overestimated, while the $\pi \rightarrow \pi^{*}$ transition satellite is underestimated ${ }^{43}$ (C 1s spectra are shown for selected carbonisation temperatures in Fig. $\mathrm{S} 5 \dagger$ ).

\subsection{Electrochemical analysis}

The activity of the PAN-derived fibres was determined using linear potential sweep voltammetry (LSV) in a half-cell setting 


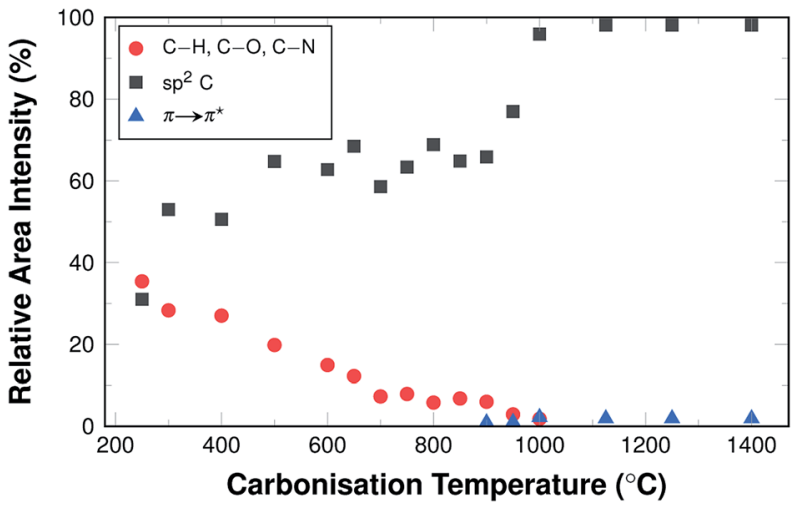

Fig. 10 Relative area intensities of XPS peaks attributed to different types of carbon and the $\pi \rightarrow \pi^{*}$ transition. A graph showing all distinguishable species is shown in Fig. S4.†

with $6 \mathrm{M} \mathrm{KOH}$ as electrolyte. The characteristic curves obtained from the measurements of samples carbonised at selected temperatures after 12 hours of immersion in $\mathrm{KOH}$ are shown in Fig. 11.

A strong dependence of the carbonisation temperature on the electrochemical behaviour is directly visible. This is true for both the open-circuit potential values and the obtained current densities. In order to clarify the trends of the electrochemical behaviour, three key values have been chosen as descriptors:

(1) The open-circuit potential $\left(E_{\mathrm{OCP}}\right)$ after $2 \mathrm{~h}$ and $12 \mathrm{~h}$ of wetting;

(2) The obtained cathodic current at a given overpotential of $20 \mathrm{mV}$ and $100 \mathrm{mV}$ relative to the $E_{\mathrm{OCP}}$ and;

(3) The required overpotential at cathodic current densities of $1 \mu \mathrm{A} \mathrm{cm}^{-2}, 10 \mu \mathrm{A} \mathrm{cm}^{-2}$, and $333 \mu \mathrm{A} \mathrm{cm}^{-2}$, corresponding to currents of $3 \mu \mathrm{A}, 30 \mu \mathrm{A}$, and $1 \mathrm{~mA}$, respectively.

The development of these key parameters with carbonisation temperature is summarised in Fig. $12 \mathrm{a}-\mathrm{c}$ and a graphic representation highlighting the mode of value determination is shown in Fig. 12d.

The $E_{\mathrm{OCP}}$ increases significantly with carbonisation temperatures up to $800{ }^{\circ} \mathrm{C}$ (Fig. 12a). The values for fibres carbonised at

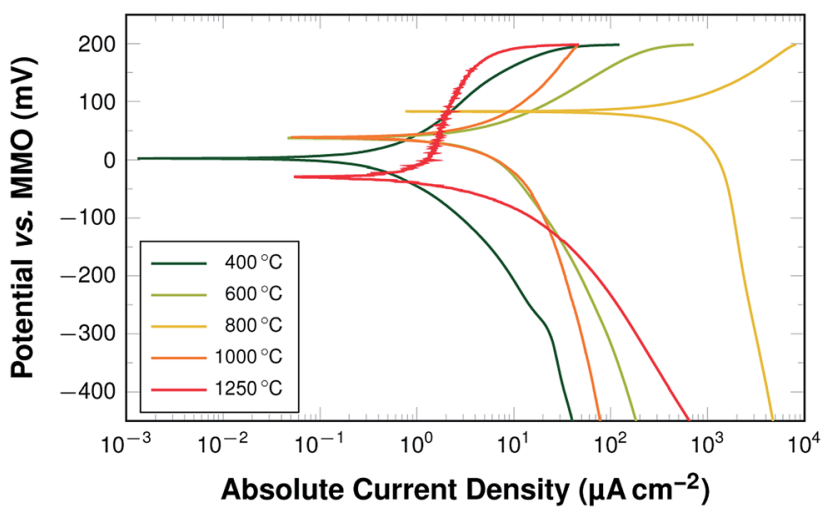

Fig. 11 Linear polarisation curves for samples carbonised at $400{ }^{\circ} \mathrm{C}$ $600{ }^{\circ} \mathrm{C}, 800{ }^{\circ} \mathrm{C}, 1000^{\circ} \mathrm{C}$, and $1250^{\circ} \mathrm{C}$; after a wetting time of $12 \mathrm{~h}$. temperatures between $800{ }^{\circ} \mathrm{C}$ and $1000{ }^{\circ} \mathrm{C}$ all lie at approximately $100 \mathrm{mV} v s$. MMO. For samples carbonised at even higher temperatures, up to $1400{ }^{\circ} \mathrm{C}$, the potential decreases again to values of about $-50 \mathrm{mV} v s$. MMO.

In the lower carbonisation temperature range, the large increase of the potential with the carbonisation temperature may be explained by the fact that at low temperatures the fibres have merely been cross-linked and retain most of the polymerlike properties of PAN. This is supported by the Raman and C $1 \mathrm{~s}$ XPS data and suggests that substantial carbonisation is only initiated at temperatures above $600{ }^{\circ} \mathrm{C}$. The low potentials for fibres carbonised at low temperatures can also be correlated to the development of the nitrogen bonding situation. Pyrrolic nitrogen and $\mathrm{N}$-oxides are present in large amounts in the fibres carbonised at low temperatures. However, according to the current understanding of oxygen redox chemistry catalysed by nitrogen-doped carbons, they contribute neither to the oxygen reduction nor to its evolution. Graphitic nitrogen, on the other hand, was shown to increase significantly with carbonisation temperature by XPS with a maximum of the absolute amount at $800{ }^{\circ} \mathrm{C}$.

In the temperature range between $700{ }^{\circ} \mathrm{C}$ and $1000{ }^{\circ} \mathrm{C}$, the fibres display an increase of only $25 \mathrm{mV}$. This correlates with the fact that in this temperature range the absolute amount of graphitic nitrogen changes only marginally. In addition to this, the overall content of nitrogen is still relatively high. It decreases from $12.5 \mathrm{wt} \%$ to $7.5 \mathrm{wt} \%$, and the fibres display a significant increase in electrical conductivity, as discussed above.

In the high temperature range the potentials decrease. For an explanation, the absolute amount of nitrogen needs to be considered. It drops to almost $0 \mathrm{wt} \%$ at $1400{ }^{\circ} \mathrm{C}$. Therefore, the catalytic activity is diminished, as pure carbon does not display substantial inherent catalytic activity towards the ORR.

The general trends are persistent with wetting time. Fibres carbonised at temperatures above $800{ }^{\circ} \mathrm{C}$ display almost constant values with wetting time. Fibres carbonised at temperatures between $300{ }^{\circ} \mathrm{C}$ and $800{ }^{\circ} \mathrm{C}$ display slightly increasing values with wetting time (Fig. 12a). The deviations amount to as much as $75 \mathrm{mV}$, especially for samples carbonised at low temperatures. The fibres carbonised at temperatures below $500{ }^{\circ} \mathrm{C}$ tend to swell, when in contact with the $\mathrm{KOH}$ electrolyte, and partially disintegrate during the measurement.

Fig. 12b shows the cathodic current density at an overpotential of $20 \mathrm{mV}$ and $100 \mathrm{mV}$ relative to the respective $E_{\mathrm{OCP}}$ as a function of the carbonisation temperature. The obtained current densities increase progressively with increasing carbonisation temperatures up to $800{ }^{\circ} \mathrm{C}$. For samples carbonised at $800{ }^{\circ} \mathrm{C}$ and $850{ }^{\circ} \mathrm{C}$ at an overpotential of $100 \mathrm{mV}$ with respect to the respective $E_{\mathrm{OCP}}$ the highest current densities are observed. They are about $1.26 \mathrm{~mA} \mathrm{~cm}^{-2}$ for samples carbonised at $850{ }^{\circ} \mathrm{C}$. The values for samples carbonised at temperatures above $850{ }^{\circ} \mathrm{C}$ decrease regressively with increasing carbonisation temperatures.

The overall trend is similar for both chosen overpotential values. The current densities are, unsurprisingly, slightly higher with a higher overpotential. This difference of the cathodic 

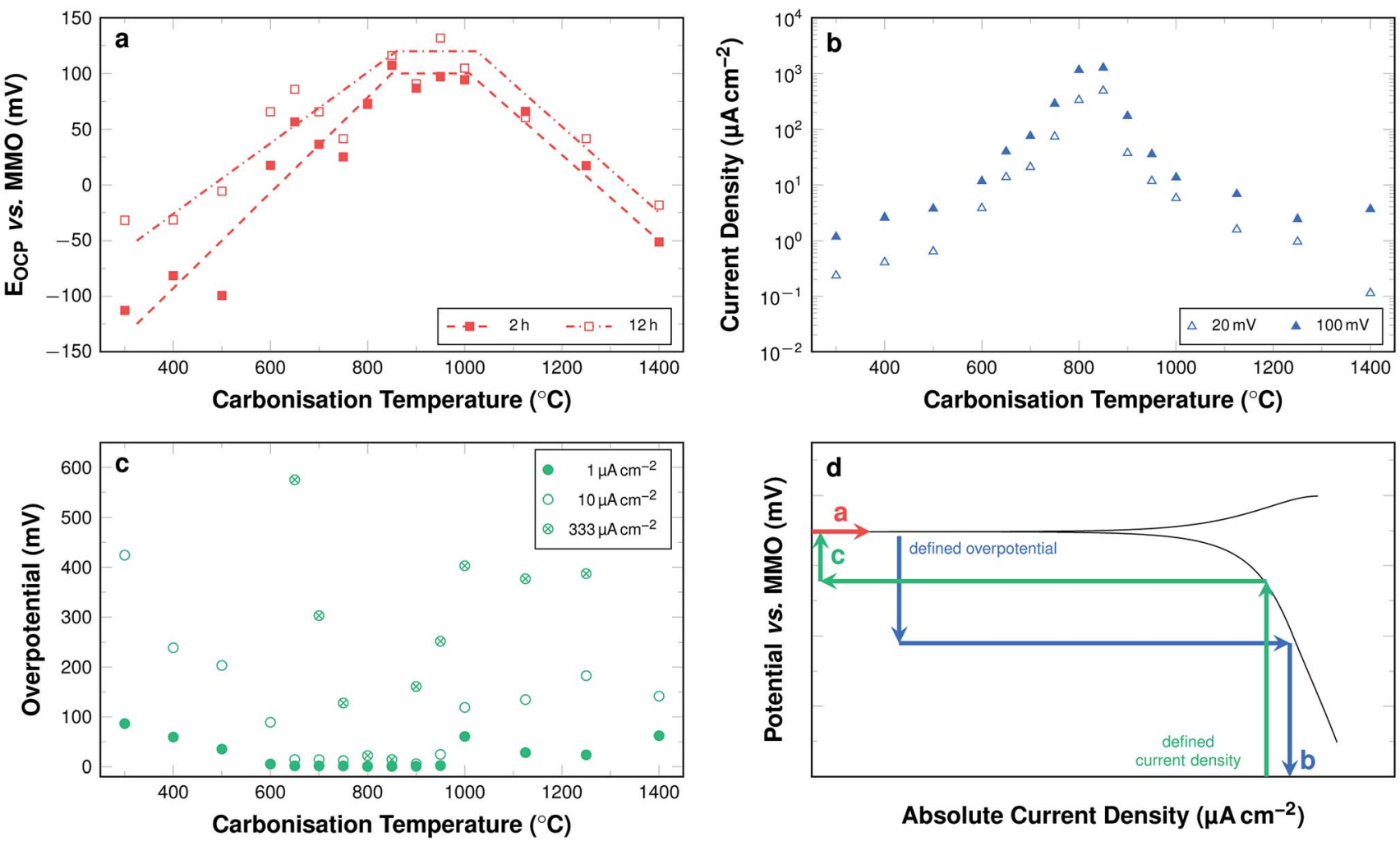

Absolute Current Density $\left(\mu \mathrm{A} \mathrm{cm}^{-2}\right)$

Fig. 12 (a) Averaged $E_{\mathrm{OCP}}$ values after $2 \mathrm{~h}$ and $12 \mathrm{~h}$ of wetting (dashed lines are guide for the eyes only). (b) Current density at a defined overpotential of $20 \mathrm{mV}$ and $100 \mathrm{mV}$ relative to individual sample $E_{\text {OCP. }}$ (c) Required overpotential to obtain current densities of $1 \mu \mathrm{A} \mathrm{cm}^{-2}, 10 \mu \mathrm{A}$ $\mathrm{cm}^{-2}$, and $333 \mu \mathrm{A} \mathrm{cm}^{-2}$. (d) Schematic illustration of linear polarisation curve displaying the modes of determination of the three investigated key parameters as shown in Fig. 11a-c.

current densities at overpotentials of $20 \mathrm{mV}$ and $100 \mathrm{mV}$ for samples carbonised at temperatures below $600{ }^{\circ} \mathrm{C}$ is larger than for the other samples. For samples carbonised between $600{ }^{\circ} \mathrm{C}$ and $1000{ }^{\circ} \mathrm{C}$ the deviation is similar for all temperatures. The obtained current density for samples carbonised at higher temperatures decreases continuously with increasing carbonisation temperatures when only low overpotentials of $20 \mathrm{mV}$ are considered. The values remain constant at around $3 \mu \mathrm{A} \mathrm{cm} \mathrm{cm}^{-2}$ when overpotentials of $100 \mathrm{mV}$ are considered.

The overpotentials in relation to the respective $E_{\mathrm{OCP}}$ required to obtain cathodic current densities of $1 \mu \mathrm{A} \mathrm{cm}^{-2}, 10 \mu \mathrm{A} \mathrm{cm}{ }^{-2}$, and $333 \mu \mathrm{A} \mathrm{cm}^{-2}$ are shown in Fig. 12c. For each investigated current density the development of the overpotential can be subdivided into four sections. A decrease, a plateau, an increase, and a second plateau. When focussing on a current density of $10 \mu \mathrm{A} \mathrm{cm}^{-2}$ samples carbonised at $300{ }^{\circ} \mathrm{C}$ require an overpotential of $424 \mathrm{mV} v s$. $E_{\mathrm{OCP}}$. This value decreases when the samples are carbonised at temperatures up to $650{ }^{\circ} \mathrm{C}$. For samples carbonised in the range between $650{ }^{\circ} \mathrm{C}$ and $900{ }^{\circ} \mathrm{C}$ the overpotential required to obtain a current density of $10 \mu \mathrm{A} \mathrm{cm}{ }^{-2}$ is close to $0 \mathrm{mV}$, i.e. the current density is readily obtained near $E_{\mathrm{OCP}}$. The overpotentials are again higher, when samples are carbonised between $900{ }^{\circ} \mathrm{C}$ and $1000{ }^{\circ} \mathrm{C}$, where they reach $118 \mathrm{mV} v s$. $E_{\mathrm{OCP}}$. The value is similar for all samples carbonised at even higher temperature up to $1400{ }^{\circ} \mathrm{C}$. While the general trends are the same for all investigated current densities, the range of the first plateau, where next to no overpotential is required for significant current densities, is narrower for higher current densities. The lowest required overpotential is found for samples carbonised at around $850{ }^{\circ} \mathrm{C}$ even at current densities of $333 \mu \mathrm{A} \mathrm{cm}{ }^{-2}$.

Overpotentials for high current densities display a minimum and likewise the obtainable current densities at given overpotentials display a maximum in samples carbonised at $850^{\circ} \mathrm{C}$. This may directly be related to a maximum in the electrocatalytic activity towards the ORR. However, it cannot be explained by the electrical and morphological properties of the fibres alone. The electrical conductivity increases with carbonisation temperature. The XPS data show that the amount of nitrogen decreases until all nitrogen is removed from the material. None of the properties investigated individually suggest, why the activity displays such a local maximum within the investigated range. Therefore, an explanation can only be found, when the results are related to each other. Summing up the behaviour of the carbon fibres discussed above, five stages can be differentiated by the carbonisation temperature across the employed techniques (Table 1). Overall, these five stages enable a description and explanation of the ORR behaviour throughout the investigated temperature range. The table elucidates especially, how the nitrogen content, but primarily the nitrogen bonding situation influences the electrochemical activity. 
Table 1 Summary of morphological, structural, electrical and electrochemical properties grouped by carbonisation temperature ranges

\begin{tabular}{|c|c|c|c|c|c|}
\hline \multirow[b]{2}{*}{ Temperature range } & Nitrogen content & $\begin{array}{l}\text { Nitrogen-type weight } \\
\text { fraction }\end{array}$ & $\begin{array}{l}\text { Electrical } \\
\text { conductivity }\end{array}$ & $\frac{I_{\mathrm{D}}^{\mathrm{a}}}{I_{\mathrm{G}}^{\mathrm{a}}}$ ratio & $\begin{array}{l}\text { Current density at given } \\
\text { overpotential } \eta\end{array}$ \\
\hline & Elemental analysis & $\begin{array}{l}\text { XPS coupled with } \\
\text { elemental analysis }\end{array}$ & Four-point probe & Raman & LSV \\
\hline \multirow{2}{*}{$300^{\circ} \mathrm{C}$ to $600^{\circ} \mathrm{C}$} & \multirow{2}{*}{ Constant at $21 \mathrm{wt} \%$} & $\begin{array}{l}\text { Pyridinic } \mathrm{N} \text { amount } \\
\text { increases }\end{array}$ & \multirow[b]{3}{*}{$\begin{array}{l}\text { No significant } \\
\text { conductivity }\end{array}$} & \multirow{2}{*}{$\begin{array}{l}\text { Decreasing from } \\
2.94 \text { to } 2.05\end{array}$} & \multirow[b]{3}{*}{$\begin{array}{l}\text { Increasing from } 1.17 \mu \mathrm{A} \mathrm{cm} \mathrm{cm}^{-2} \text { to } \\
1263 \mu \mathrm{A} \mathrm{cm}^{-2} \text { at } \eta=100 \mathrm{mV}\end{array}$} \\
\hline & & $\begin{array}{l}\text { Amounts of other } \mathrm{N} \text { types } \\
\text { decrease }\end{array}$ & & & \\
\hline $600^{\circ} \mathrm{C}$ to $800^{\circ} \mathrm{C}$ & \multirow[t]{2}{*}{$\begin{array}{l}\text { Decreasing from } 21 \mathrm{wt} \% \\
\text { to } 6 \mathrm{wt} \%\left(0.04 \mathrm{wt}^{\mathrm{t}} \% \mathrm{~K}^{-1}\right)\end{array}$} & $\begin{array}{l}\text { Graphitic } \mathrm{N} \text { amount } \\
\text { increases, pyridinic } \mathrm{N} \text { and } \\
\text { pyrrolic } \mathrm{N} \text { amounts } \\
\text { decrease, } \mathrm{N} \text {-oxide amount } \\
\text { does not change } \\
\text { significantly }\end{array}$ & & \multirow[t]{2}{*}{$\begin{array}{l}\text { Decreasing from } \\
2.05 \text { to } 1.92\end{array}$} & \\
\hline $800^{\circ} \mathrm{C}$ to $1000^{\circ} \mathrm{C}$ & & \multirow{3}{*}{ All $N$ types decrease } & $\begin{array}{l}\text { Increasing from } \\
0.25 \mathrm{~S} \mathrm{~cm}^{-1} \text { to } \\
1.86 \mathrm{~S} \mathrm{~cm}^{-1}\end{array}$ & & \multirow{3}{*}{$\begin{array}{l}\text { Decreasing from } 1263 \mu \mathrm{A} \mathrm{cm}^{-2} \\
\text { to } 3.65 \mu \mathrm{A} \mathrm{cm} \mathrm{cm}^{-2} \text { at } \eta=100 \mathrm{mV}\end{array}$} \\
\hline $1000^{\circ} \mathrm{C}$ to $1200{ }^{\circ} \mathrm{C}$ & \multirow{2}{*}{$\begin{array}{l}\text { Decreasing from } 6 \mathrm{wt} \% \text { to } \\
2 \mathrm{wt} \%\left(0.01 \mathrm{wt} \% \mathrm{~K}^{-1}\right)\end{array}$} & & $\begin{array}{l}\text { Increasing from } \\
1.86 \mathrm{~S} \mathrm{~cm}^{-1} \text { to } \\
2.51 \mathrm{~S} \mathrm{~cm}^{-1}\end{array}$ & Almost constant at & \\
\hline $1200^{\circ} \mathrm{C}$ to $1400^{\circ} \mathrm{C}$ & & & $\begin{array}{l}\text { Increasing from } \\
2.51 \mathrm{~S} \mathrm{~cm}^{-1} \text { to } \\
4.62 \mathrm{~S} \mathrm{~cm}^{-1}\end{array}$ & & \\
\hline
\end{tabular}

Positive potentials, low overpotentials, and high cathodic currents at given overpotentials correlate with the amount of graphitic nitrogen. It is expected that the potential increases with increaseing amounts of graphitic nitrogen, however, this is not the case. This is likely the result of the reduction of the overall amount of nitrogen, but also due to the fact that increasing graphite-like ordering (as discussed for the Raman results) implies a reduction of edge regions, which are known to be more active. ${ }^{30}$ Furthermore, in this temperature range the amount of pyridinic nitrogen is reduced, which may likewise reduce ORR activity. ${ }^{22,27}$

\section{Conclusions}

The behaviour of electrospun PAN-derived carbon fibres as a framework for air electrodes for aqueous-alkaline metal-air batteries has been investigated in a comprehensive approach. The focus of this investigation was the influence of the carbonisation temperature in a temperature range between $300{ }^{\circ} \mathrm{C}$ and $1400{ }^{\circ} \mathrm{C}$ on structure, (surface) chemistry of nitrogen, electrical conductivity and electrochemical characteristics of the fibres.

As the carbonisation temperature increases, the amount of nitrogen is reduced from more than $20 \mathrm{wt} \%$ to approximately $2 \mathrm{wt} \%$. Likewise, the bonding situation of the nitrogen shifts from pyridinic/pyrrolic to purely graphitic, as was demonstrated by XPS. A correlation between nitrogen content, structure, and electrical conductivity was found. For fibres carbonised at temperatures higher than $600{ }^{\circ} \mathrm{C}$ the conductivity of the materials increases. This appears to be the case, once the transformation of the material from polymer-like to graphite-like is initiated. It follows from elemental analysis and Raman spectroscopy, that this transformation is accompanied-if not caused-by the removal of the hetero-species from the structure. The data suggest a dominant influence of the nitrogen removal on this transformation process, compared to a more indirect influence of oxygen and hydrogen.

Evaluation of open circuit potentials, the cathodic currents at given overpotentials, and required overpotentials at given current densities suggest the highest ORR activities for fibres carbonised in the temperature range from $800{ }^{\circ} \mathrm{C}$ to $900{ }^{\circ} \mathrm{C}$. The nitrogen bonding situation correlates with the ORR activity of the material, indicating that a high nitrogen content in form of graphitic and pyridinic nitrogen along with sufficient electronic conductivity favours high cathodic current densities. Therefore, our findings support the assumption, that the graphitic nitrogen controls the catalytic activity and that the amount of nitrogen plays a vital role.

Carbon fibres from a PAN precursor show a decent activity towards ORR and feature appreciable electrical properties for applications in aqueous metal-air batteries. The electrochemical behaviour can be influenced by varying the nitrogen content and bonding state via temperature adjustment during the carbonisation process.

\section{Conflicts of interest}

There are no conflicts to declare.

\section{Acknowledgements}

Funding by the German Federal Ministry of Education and Research (BMBF) project LuZi Air-zinc batteries with innovative materials for the storage of regenerative energies and grid stabilisation (project no. 03SF0499F) and project SABLE (project no. 03EK3543) is acknowledged. The authors thank the Central 
Institute for Engineering, Electronics and Analytics (ZEA-3) of Forschungszentrum Jülich $\mathrm{GmbH}$ for performing the elemental analysis and X-ray photo spectroscopy measurements and data analysis.

\section{Notes and references}

1 V. Caramia and B. Bozzini, Mater. Renew. Sustain. Energy, 2014, 3, 1-12.

2 Y. Shimizu, J. Electrochem. Soc., 1990, 137, 3430-3433.

3 X. Zhang, X.-G. Wang, Z. Xie and Z. Zhou, Green Energy Environ., 2016, 1, 4-17.

4 H. Weinrich, M. Gehring, H. Tempel, H. Kungl and R.-A. Eichel, J. Appl. Electrochem., 2018, 48, 451-462.

5 H. Weinrich, Y. E. Durmus, H. Tempel, H. Kungl and R.-A. Eichel, Materials, 2019, 12, 1-55.

6 P. Jakes, G. Cohn, Y. Ein-Eli, F. Scheiba, H. Ehrenberg and R.-A. Eichel, ChemSusChem, 2012, 5, 2278-2285.

7 L. Jörissen, J. Power Sources, 2006, 155, 23-32.

8 L. Zhang, A. Aboagye, A. Kelkar, C. Lai and H. Fong, J. Mater. Sci., 2014, 49, 463-480.

9 M. Inagaki, Y. Yang and F. Kang, Adv. Mater., 2012, 24, 25472566.

10 J. Li, E.-H. Liu, W. Li, X.-Y. Meng and S.-T. Tan, J. Alloys Compd., 2009, 478, 371-374.

11 B. Li, S.-W. Chien, X. Ge, J. Chai, X.-Y. Goh, K.-T. Nai, T. S. A. Hor, Z. Liu and Y. Zong, Mater. Chem. Front., 2017, 1, 677-682.

12 Y. Liu, C. Duong-Viet, J. Luo, A. Hébraud, G. Schlatter, O. Ersen, J.-M. Nhut and C. Pham-Huu, ChemCatChem, 2015, 7, 2957-2964.

13 E. S. Davydova, A. Y. Rychagov, I. I. Ponomarev and I. I. Ponomarev, Russ. J. Electrochem., 2013, 49, 1010-1011.

14 A. Shindo, Report no. 317, Osaka Industrial Research Institute report, 1961.

15 W. Watt, in Chemistry and Physics of the Conversion of Polyacrylonitrile Fibres into High-Modulus Carbon Fibres, ed. W. Watt and B. Perov, Elsevier Science Publishers B.V., Amsterdam, 1985, vol. 1, book section 9, pp. 327-387.

16 R. Schierholz, D. Kröger, H. Weinrich, M. Gehring, H. Tempel, H. Kungl, J. Mayer and R.-A. Eichel, RSC Adv., 2019, 9, 6267-6277.

17 W. Watt, Nat. Phys. Sci., 1972, 236, 10-11.

18 X. Zou, L. Wang and B. I. Yakobson, Nanoscale, 2018, 10, 1129-1134.

19 Y. Zhao, L. Yang, S. Chen, X. Wang, Y. Ma, Q. Wu, Y. Jiang, W. Qian and Z. Hu, J. Am. Chem. Soc., 2013, 135, 1201-1204.

20 Z.-L. Wang, D. Xu, J.-J. Xu and X.-B. Zhang, Chem. Soc. Rev., 2014, 43, 7746-7786.

21 J. Zhang, Z. Zhao, Z. Xia and L. Dai, Nat. Nanotechnol., 2015, 10, 444-452.
22 S. Bag and C. R. Raj, J. Chem. Sci., 2016, 128, 339-347.

23 N. Wang, B. Lu, L. Li, W. Niu, Z. Tang, X. Kang and S. Chen, ACS Catal., 2018, 8, 6827-6836.

24 Q. Lv, W. Si, J. He, L. Sun, C. Zhang, N. Wang, Z. Yang, X. Li, X. Wang, W. Deng, Y. Long, C. Huang and Y. Li, Nat. Commun., 2018, 9, 1-11.

25 D. Geng, Y. Chen, Y. Chen, Y. Li, R. Li, X. Sun, S. Ye and S. Knights, Energy Environ. Sci., 2011, 4, 760-764.

26 L. Lai, J. R. Potts, D. Zhan, L. Wang, C. K. Poh, C. Tang, H. Gong, Z. Shen, J. Lin and R. S. Ruoff, Energy Environ. Sci., 2012, 5, 7936-7942.

27 T. Xing, Y. Zheng, L. H. Li, B. C. C. Cowie, D. Gunzelmann, S. Z. Qiao, S. Huang and Y. Chen, ACS Nano, 2014, 8, 6856-6862.

28 Z. Shi, J. Zhang, Z.-S. Liu, H. Wang and D. P. Wilkinson, Electrochim. Acta, 2006, 51, 1905-1916.

29 L. Yu, X. Pan, X. Cao, P. Hu and X. Bao, J. Catal., 2011, 282, 183-190.

30 X. Ge, A. Sumboja, D. Wuu, T. An, B. Li, F. W. T. Goh, T. S. A. Hor, Y. Zong and Z. Liu, ACS Catal., 2015, 5, 46434667.

31 K. Gong, F. Du, Z. Xia, M. Durstock and L. Dai, Science, 2009, 323, 760-764.

32 H. Kim, K. Lee, S. I. Woo and Y. Jung, Phys. Chem. Chem. Phys., 2011, 13, 17505-17510.

33 D. Guo, R. Shibuya, C. Akiba, S. Saji, T. Kondo and J. Nakamura, Science, 2016, 351, 361-365.

34 I. Miccoli, F. Edler, H. Pfnur and C. Tegenkamp, J. Phys.: Condens. Matter, 2015, 27, 1-29.

35 Y. Yang, F. Simeon, T. A. Hatton and G. C. Rutledge, J. Appl. Polym. Sci., 2012, 124, 3861-3870.

36 B. Saha and G. C. Schatz, J. Phys. Chem. B, 2012, 116, 46844692.

37 A. V. Gribanov and Y. N. Sazanov, Russ. J. Appl. Chem., 2008, 81, 919-932.

38 A. Sadezky, H. Muckenhuber, H. Grothe, R. Niessner and U. Pöschl, Carbon, 2005, 43, 1731-1742.

39 A. C. Ferrari and J. Robertson, Phys. Rev. B Condens. Matter Mater. Phys., 2000, 61, 14095-14107.

40 W. Otting, Der Raman-Effekt und seine analytische Anwendung, Springer-Verlag, Berlin, 1952.

41 Z. R. Ismagilov, A. E. Shalagina, O. Y. Podyacheva, A. V. Ischenko, L. S. Kibis, A. I. Boronin, Y. A. Chesalov, D. I. Kochubey, A. I. Romanenko, O. B. Anikeeva, T. I. Buryakov and E. N. Tkachev, Carbon, 2009, 47, 19221929.

42 C. Kim, S.-H. Park, J.-I. Cho, D.-Y. Lee, T.-J. Park, W.-J. Lee and K.-S. Yang, J. Raman Spectrosc., 2004, 35, 928-933.

43 S. R. Kelemen, K. D. Rose and P. J. Kwiatek, Appl. Surf. Sci., 1993, 64, 167-174. 